\title{
The world's tallest nation has stopped growing taller: the height of Dutch children from 1955 to 2009
}

\author{
Yvonne Schönbeck', Henk Talma ${ }^{2}$, Paula van Dommelen ${ }^{3}$, Boudewijn Bakker ${ }^{4}$, Simone E. Buitendijk' ${ }^{1}$ Remy A. HiraSing ${ }^{2}$ and \\ Stef van Buuren ${ }^{3}$
}

BACKGROUND: Records show that mean height in The Netherlands has increased since 1858. This study looks at whether this trend in the world's tallest nation is continuing. We consider the influence of the geographical region, and of the child and parental education, on changes in height.

METHODS: We compared the height of young Dutch people aged 0-21 y as determined on the basis of the growth study of 2009, with the height data from growth studies conducted in 1955, 1965, 1980, and 1997.

RESULTS: The analysis sample included 5,811 boys and 6,194 girls. Height by age was the same as in 1997. Mean final height was $183.8 \mathrm{~cm}(\mathrm{SD}=7.1 \mathrm{~cm})$ in boys and $170.7 \mathrm{~cm}(\mathrm{SD}=6.3 \mathrm{~cm})$ in girls. The educational levels of both children and their parents are positively correlated with mean height. Since 1997, differences between geographical regions have decreased but not vanished, with the northern population being the tallest.

CONCLUSION: The world's tallest population has stopped growing taller after a period of $150 \mathrm{y}$, the cause of which is unclear. The Dutch may have reached the optimal height distribution. Alternatively, growth-promoting environmental factors may have stabilized in the past decade, preventing the population from attaining its full growth potential.

O ver the past decades, human height has increased in most industrialized countries. This trend has been the result of improvements in the nutritional, hygienic, economic, and health status of the populations in question (1). Such factors may allow disadvantaged individuals in particular to grow taller. However, we have not found any reduction in height variation (2). It appears that individuals benefit more or less equally from improvements in living conditions. Do we believe that we could all be giants if living conditions for humans were to improve further, or is there some maximum (and presumably optimal) population average beyond which our species will not grow, no matter how favorable the circumstances? Although being tall is often associated with being healthy, this may not always be the case. Taller adults have, for example, higher rates of several types of cancer (3). The question of whether there is a maximum population average is almost impossible to answer, but studies of trends in mean height and of height variations in tall populations could suggest a possible direction.

The Dutch population is the tallest in the world and has been well studied. Before 1955, population height in The Netherlands was estimated on the basis of data for conscripts, i.e., men, and nonrandom samples from the population. Between 1955 and 1997, there were four large cross-sectional nationwide growth studies. These studies showed that young Dutch adults are among the tallest people in the world, with women measuring almost $171 \mathrm{~cm}$ on average and men $184 \mathrm{~cm}$ on average in 1997 (4).

In The Netherlands, people have been getting taller since $1858(2,5)$. At that time, conscripts were an average of $163 \mathrm{~cm}$. This indicates a height gain of $21 \mathrm{~cm}$ over a period of $140 \mathrm{y}$. In The Netherlands, as in most Northern European countries, the upward trend is slowing down significantly $(2,6)$, and it even appears to be reversing in the United States (7).

This article presents new data about height from the Fifth Dutch Growth Study, which was carried out in 2009. The main research questions are: Is the 140-y trend of increasing height in the world's tallest nation still continuing? If not, has there been a compression of height variation? Do geographical region and educational levels affect the development of mean height?

\section{RESULTS}

The sample comprised of 10,030 children of Dutch origin and 1,975 imputed cases, resulting in an analysis sample of 12,005 children (5,811 boys and 6,194 girls) aged 0-21 y. Table 1 lists the numbers of children in each age group.

Height by age and sex was normally distributed, and therefore standard deviation scores (SDS) could easily be calculated as (height - mean height)/SD. Table 2 summarizes the mean and SD for height extracted from the height references, classified according to age and sex. Extended tables are available from the authors on request.

New growth diagrams were constructed for boys and girls aged $0-21 \mathrm{y}$, including $2.5,2,1,0,-1,-2,-2.5$, and $-3 \mathrm{SD}$ lines. The -3 SD line was added for practical reasons because the Dutch referral criteria require children with a height SDS of less than -3 SD to be referred for short stature. Figure 1a,b shows the new growth diagrams for boys and girls aged 1-21 y. 
Table 1. Number of observations per age and sex in the Fifth Dutch Growth Study 2009

\begin{tabular}{|c|c|c|}
\hline Age (y) & Boys $(n)$ & Girls (n) \\
\hline $0-1$ & 999 & 992 \\
\hline $1-2$ & 536 & 543 \\
\hline $2-3$ & 343 & 349 \\
\hline $3-4$ & 311 & 308 \\
\hline $4-5$ & 138 & 184 \\
\hline $5-6$ & 187 & 214 \\
\hline $6-7$ & 161 & 210 \\
\hline $7-8$ & 202 & 224 \\
\hline $8-9$ & 226 & 246 \\
\hline $9-10$ & 233 & 254 \\
\hline $10-11$ & 318 & 367 \\
\hline $11-12$ & 280 & 287 \\
\hline $12-13$ & 255 & 294 \\
\hline $13-14$ & 196 & 235 \\
\hline $14-15$ & 256 & 307 \\
\hline $15-16$ & 245 & 265 \\
\hline $16-17$ & 163 & 178 \\
\hline $17-18$ & 205 & 179 \\
\hline 18-19 & 180 & 185 \\
\hline $19-20$ & 166 & 158 \\
\hline $20-21$ & 137 & 165 \\
\hline $21-22$ & 74 & 50 \\
\hline Total & 5,811 & 6,194 \\
\hline
\end{tabular}

Similar growth diagrams were established for children aged $0-15$ mo and $0-4 \mathrm{y}$. Note that there is no visual evidence of the pubertal height growth spurt in the growth diagram for girls.

Figure 2 shows the trend in the mean final height in boys and girls from 1955 to 2009. The figure illustrates that the upward secular trend in the mean final height of young Dutch adults has stopped. Mean final height was $183.8 \mathrm{~cm}(\mathrm{SD}=7.1 \mathrm{~cm})$ in Dutch boys and $170.7 \mathrm{~cm}(\mathrm{SD}=6.3 \mathrm{~cm})$ in Dutch girls. These heights do not differ significantly from the heights in 1997 $(184.0 \mathrm{~cm}$ for boys and $170.6 \mathrm{~cm}$ for girls). Figure 2 indicates that the pace of the increase in secular height over the years slowed down both in boys and girls, falling to almost zero in 2009.

Figure 3 shows, for Dutch children aged 1-21 y, the height difference with respect to 1955 in 1965, 1980, 1997, and 2009 for each age. The figure clearly shows an increase in height for the period 1955-1997, especially from the age of $4 \mathrm{y}$ onward, with the increase being more marked in boys than in girls. This figure also shows that the secular trend has stopped since 1997, not only for final height but also for all ages, with the 1997 and 2009 lines being a close match for all ages. There is only a small difference in height at the ages of 11-13 y in boys and girls and at the age of $15 \mathrm{y}$ in boys. These differences are more pronounced in boys $(0.7-1.2 \mathrm{~cm})$ than in girls $(0.4-0.5 \mathrm{~cm})$. This may indicate slightly earlier puberty.
Table 2. Mean height and SD extracted from height references for boys and girls per age

\begin{tabular}{|c|c|c|c|c|}
\hline \multirow[b]{3}{*}{ Age (y) } & \multicolumn{4}{|c|}{ Height } \\
\hline & \multicolumn{2}{|c|}{ Boys } & \multicolumn{2}{|c|}{ Girls } \\
\hline & Mean & SD & Mean & SD \\
\hline $0.0767^{a}$ & 54.4 & 2.3 & 53.7 & 2.3 \\
\hline 0.2500 & 60.9 & 2.4 & 59.7 & 2.4 \\
\hline 0.5000 & 68.0 & 2.5 & 66.4 & 2.5 \\
\hline 0.7500 & 72.9 & 2.6 & 72.9 & 2.6 \\
\hline 1.0000 & 76.7 & 2.7 & 75.0 & 2.8 \\
\hline 1.2500 & 79.9 & 2.8 & 78.4 & 2.9 \\
\hline 1.5000 & 82.8 & 2.9 & 81.5 & 3.1 \\
\hline 1.7500 & 85.6 & 3.1 & 84.4 & 3.2 \\
\hline 2.0000 & 88.4 & 3.2 & 87.1 & 3.3 \\
\hline 3.0000 & 97.8 & 3.7 & 97.0 & 3.8 \\
\hline 4.0000 & 105.5 & 4.2 & 104.9 & 4.2 \\
\hline 5.0000 & 113.2 & 4.7 & 112.1 & 4.7 \\
\hline 6.0000 & 119.9 & 5.1 & 118.8 & 5.1 \\
\hline 7.0000 & 126.2 & 5.4 & 125.3 & 5.4 \\
\hline 8.0000 & 132.5 & 5.8 & 131.3 & 5.8 \\
\hline 9.0000 & 138.5 & 6.2 & 137.3 & 6.1 \\
\hline 10.0000 & 143.7 & 6.6 & 143.5 & 6.5 \\
\hline 11.0000 & 149.0 & 7.0 & 149.7 & 6.7 \\
\hline 12.0000 & 155.2 & 7.6 & 155.7 & 6.9 \\
\hline 13.0000 & 161.8 & 8.2 & 160.8 & 6.9 \\
\hline 14.0000 & 168.5 & 8.3 & 164.5 & 6.9 \\
\hline 15.0000 & 175.2 & 7.9 & 166.9 & 6.8 \\
\hline 16.0000 & 179.1 & 7.6 & 168.3 & 6.7 \\
\hline 17.0000 & 181.0 & 7.4 & 169.2 & 6.6 \\
\hline 18.0000 & 182.4 & 7.2 & 169.7 & 6.5 \\
\hline 19.0000 & 183.6 & 7.1 & 170.1 & 6.4 \\
\hline 20.0000 & 183.8 & 7.1 & 170.5 & 6.3 \\
\hline 21.0000 & 183.8 & 7.1 & 170.7 & 6.3 \\
\hline
\end{tabular}

${ }^{\mathrm{a}} 0.0767=4 \mathrm{wk}$.

Figure 4 presents the mean height SDS of Dutch children aged $0-21$ y by geographical region, level of child education, and level of parental education in 1997 and 2009, corrected for each of the two other factors. Variation across the geographical regions has lessened since 1997. The mean height SDS in the north and in the south are closer to the overall mean (Figure 4a). The mean height SDS in the north of the country is still significantly higher than that in the south (difference = 0.22 SDS; $P<0.001)$ and the major cities (0.12 SDS; $P=0.018$ ). This means that $21-y$-old boys and girls from the north are on average 1.6 and $1.4 \mathrm{~cm}$ taller, respectively, than those from the south. Figure 4b,c shows that, in 2009, as in 1997, mean height SDS increased in line with the educational levels of children and their parents. Since 1997, mean height SDS has not changed significantly. Nevertheless, the mean height SDS of children with lower levels of education was significantly lower than that 
a

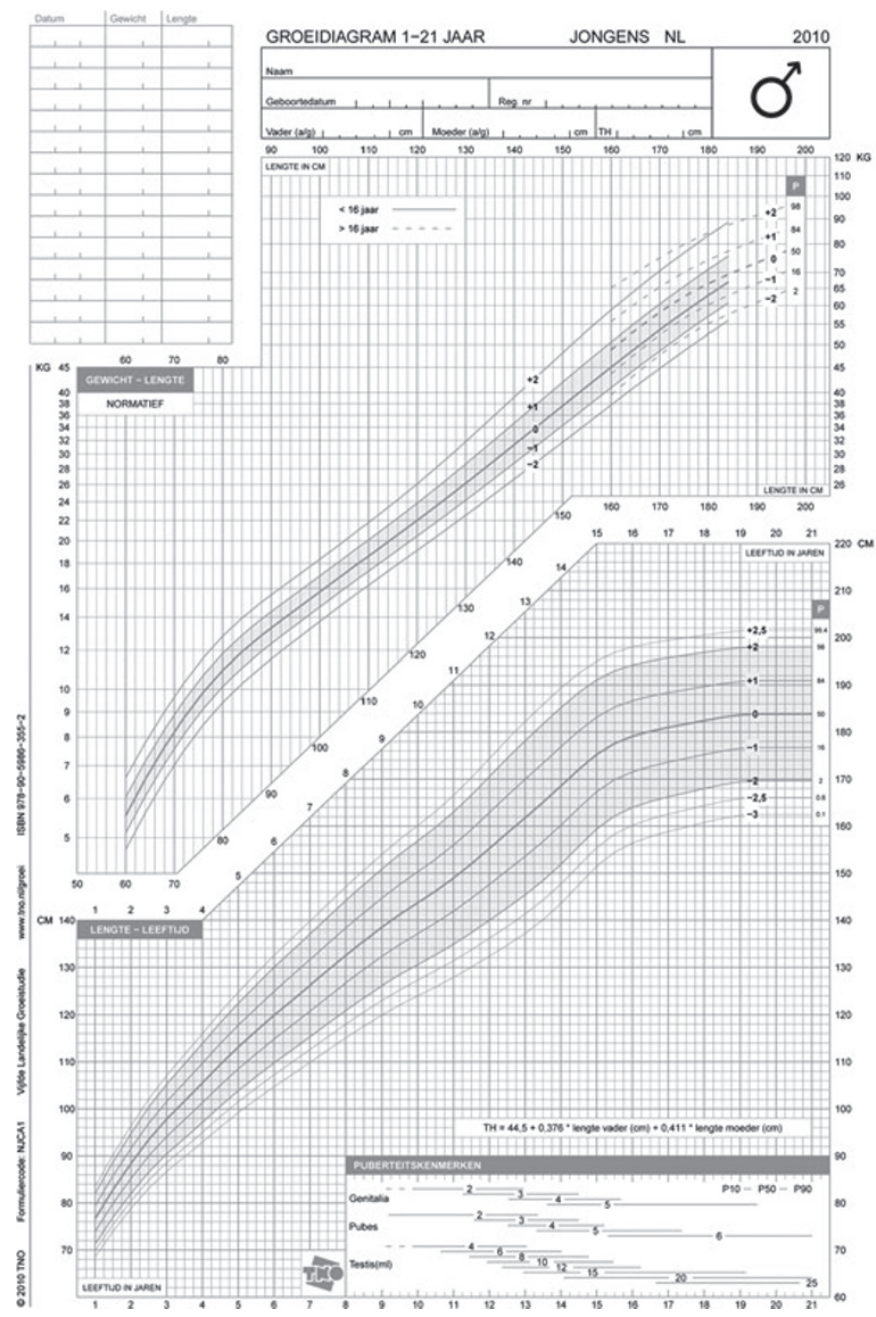

b

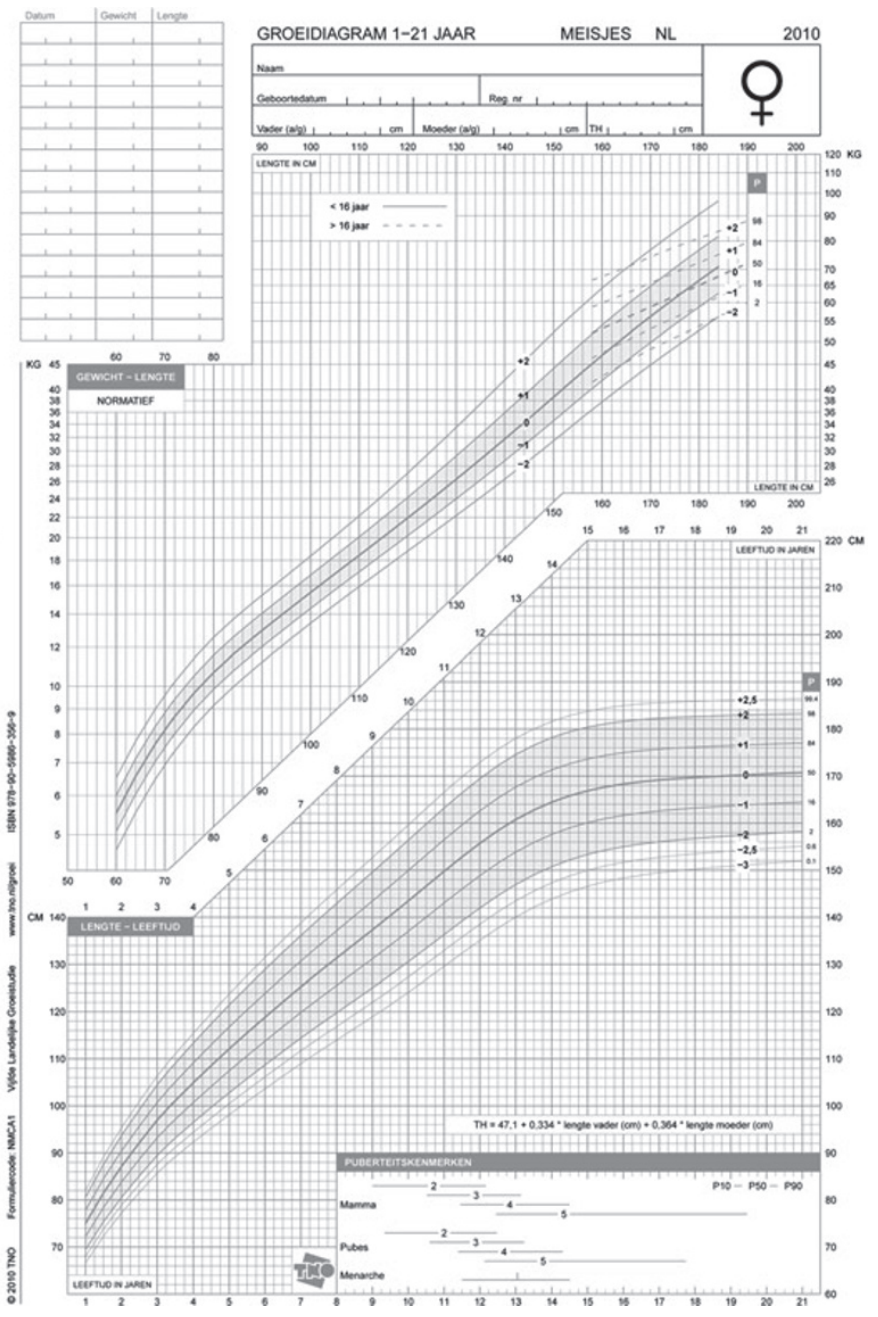

Figure 1. New Dutch growth diagrams, including height by age references for (a) boys and (b) girls aged 1-21 y.

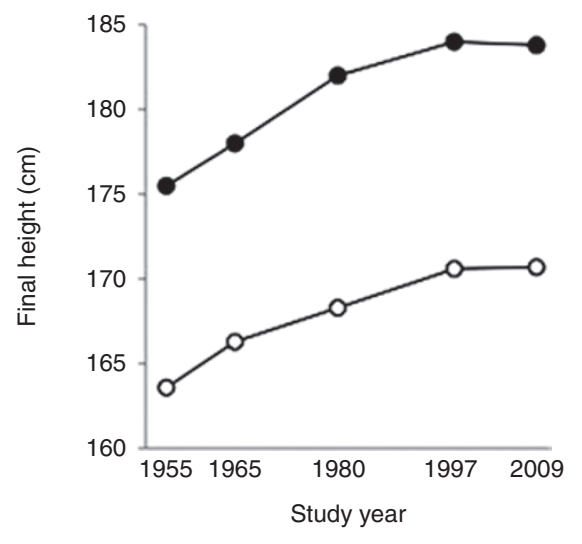

Figure 2. Mean final height in Dutch boys (filled circles) and girls (open circles) in 1955-2009.

of those with higher levels of education in $2009(P=0.003)$, whereas this difference was nonsignificant in $1997(P=0.438)$, indicating that $21 \mathrm{y}$ olds with lower levels of education are on average $1.4 \mathrm{~cm}$ (boys) and $1.2 \mathrm{~cm}$ (girls) shorter than those with higher levels of education. At the age of $21 \mathrm{y}$, boys of lower- educated parents are on average $0.8 \mathrm{~cm}$ shorter than those of higher-educated parents. For girls, this difference is $0.7 \mathrm{~cm}$.

\section{DISCUSSION}

This study shows that the height of Dutch children in 2009 is very similar to that in 1997 . There was a slight increase in mean height in early puberty in boys and girls, indicating that they were taller at a younger age than in 1997. However, this did not affect the final height, as no significant differences in final height were seen as compared with 1997. There was no compression of height variation observed.

It is remarkable that the secular height trend spanning 150 $y$ has come to an end, at least temporarily. The cause is not yet clear. Economic factors are not likely to be involved because gross domestic product in The Netherlands did not level off; indeed, it rose exponentially between 1920 and 2008 (8). We also looked at the course of the Life Situation Index (LSI) between 1974 and 2008. This index was established by The Netherlands Institute for Social Research to measure the progress of Dutch society using indicators that go beyond mere economic growth. The index incorporates indicators in eight 


\section{Articles $\mid$ Schönbeck et al.}
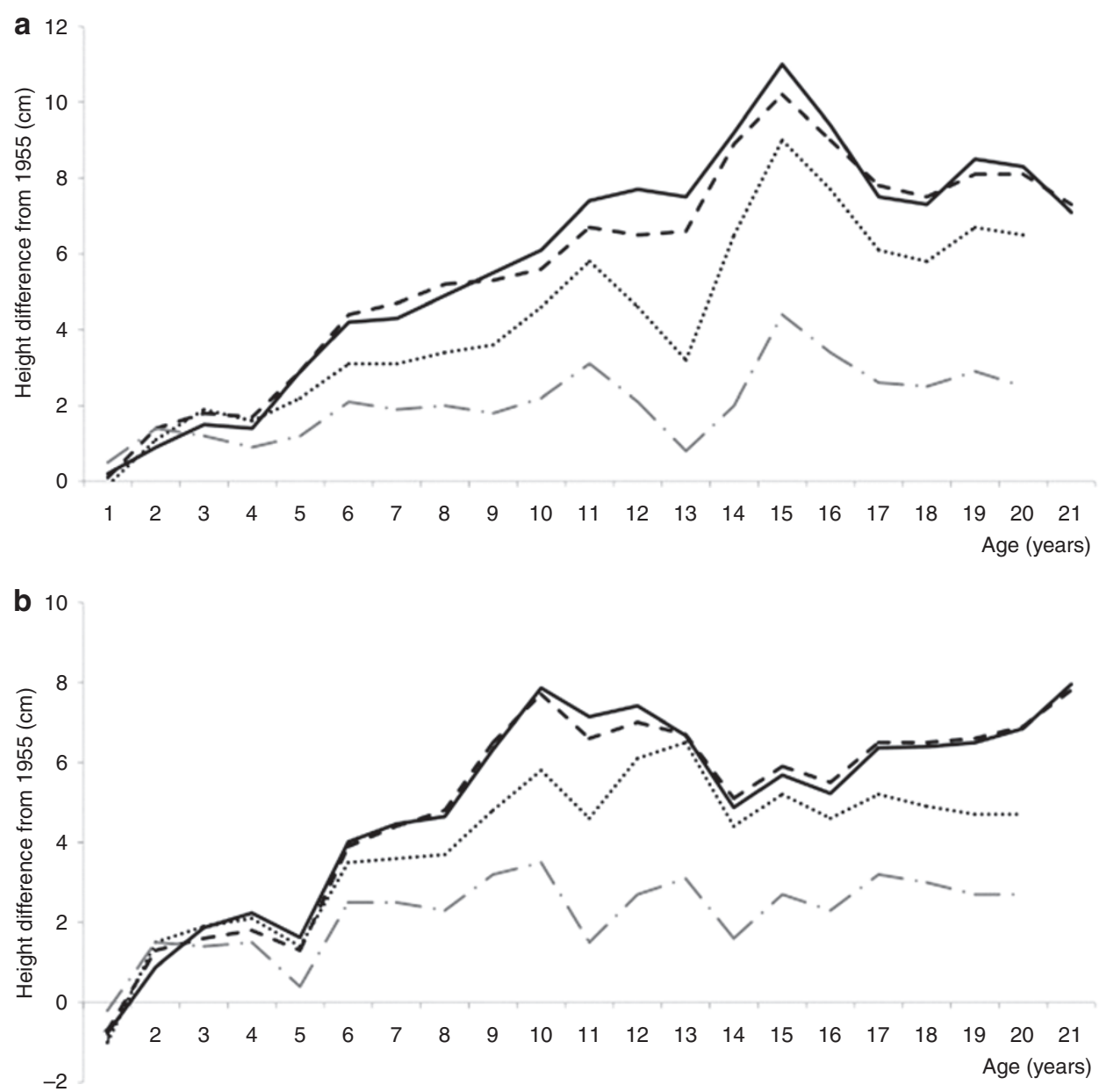

Figure 3. Height increase since 1955 by age in Dutch (a) boys and (b) girls in 2009 (solid line), 1997 (striped line), 1980 (dotted line), and 1965 (gray striped lines).

domains: health, sport, social participation (loneliness, volunteering), cultural/leisure activities, housing, mobility, holidays, and possession of assets $(9,10)$. The LSI rose substantially between 1974 and 2008. Between 1990 and 2008, the differences in LSI scores between socioeconomic classes decreased. This was mainly due to a higher rise in the LSI score for lower socioeconomic groups (9). A correlation between height and LSI has not been demonstrated, but one would expect a positive correlation, as with economic growth. The rise in LSI mentioned here and the reduction in the variation in LSI scores across socioeconomic groups do not therefore explain the break in the Dutch height trend. Children of parents born outside The Netherlands were excluded from the analyses. The so-called third-generation immigrants-those with parents born in The Netherlands but grandparents born outside The Netherlands-were not excluded. This group makes up an increasing proportion of the population in The Netherlands but is still relatively small. On the basis of data on the country of birth of the grandparents, only $4-5 \%$ of our study population were from the third generation. Although the third-generation immigrants may be partly accountable for the flattening of the Dutch growth trend, this group is too small to fully explain the stagnation in height. Moreover, children known to have a diagnosed growth disorder or who were on growth-interfering medication were excluded from the sample. It is possible that some growth disorders and growth-interfering medication were not mentioned by a child or parent, or were not in the medical records and therefore were missed by the health-care provider. This could lead to an underestimation of mean height per age. However, we believe that even if we missed some children, they would form only a very small part of the sample size per age. Moreover, the same method for inquiring about and exclusion of growth disorders and medication was applied in 1997. Therefore, it is unlikely that growth disorders and growth-interfering medication influenced the height difference between 1997 and 2009.

There will always be some differences in, for example, the genetic background and socioeconomic status in a given population, leading to height variations. Given that the Dutch are the tallest people in the world, and that they are no longer growing taller, we could hypothesize that the mean height of the population has reached the maximum possible. It could be that the distribution of population characteristics in The Netherlands, including environmental factors, is the "best" achievable at the country level, leading to a mean population height of $184 \mathrm{~cm}$ for boys and $171 \mathrm{~cm}$ for girls. 

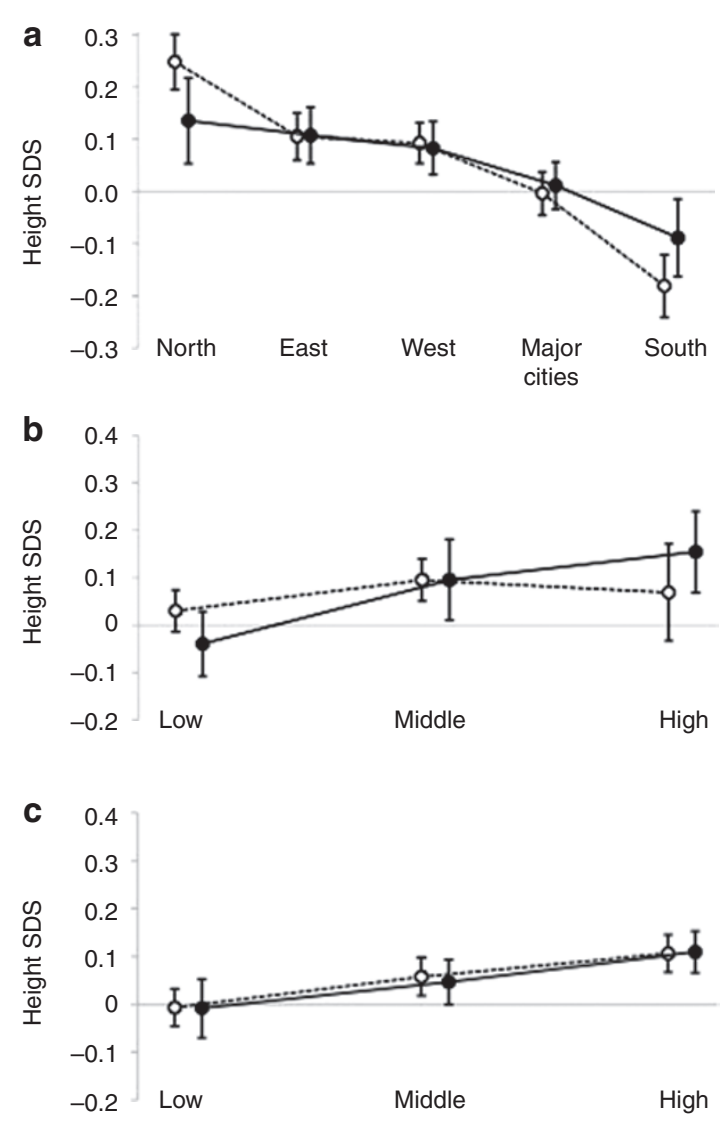

Figure 4. Differences in height SDS by (a) geographical region, (b) educational level of the child, and (c) highest completed education of parents between 1997 (open circles) and 2009 (filled circles). Values are means, adjusted for the effects of the other factors. SDS, standard deviation scores.

Alternatively, growth-promoting environmental factors may have stabilized in the past decade, preventing the Dutch from fulfilling their full growth potential. We could hypothesize that current lifestyles have a negative effect on height. Komlos (11), who looked at differences in height and BMI between Dutch and US children, also suggested this. Where insufficient food intake may have led to stunting decades ago, easy access to food/fast food nowadays leads to unhealthy eating habits. For example, the high consumption of milk in The Netherlands, which has been linked to tallness (12), declined over the past decade from 631 per capita per year in 2000 to 60 in 2010 (13). Unhealthy eating habits may lead to inadequate nutrient intake, which may result in lower height. Furthermore, an unhealthy diet in combination with less energy expenditure due to a sedentary lifestyle leads to an increase in overweight and obesity, a phenomenon that has also been observed in Dutch children (14). Higher BMI is associated with earlier onset of maturation and menarche, which, in turn, are related to lower height $(15,16)$. If our hypothesis is valid, adopting healthier lifestyles (including healthier diet and more activity) could result in the reemergence of the positive height trend in the future.

No pubertal height growth spurt can be observed in the growth diagram for girls. This is due to the fact that $\mathrm{Dutch}$ growth studies are cross-sectional studies. These growth diagrams are suitable for monitoring child height over time, but one should bear in mind that these charts do not fully represent how an individual child typically grows.

Only children with both parents born in The Netherlands were included. The selection of children of Dutch decent may complicate comparisons of height/final height between countries because some countries include all ethnic groups in their data. On the basis of data for other ethnic groups in the dataset of the Fifth Dutch Growth Study, we estimated an adjusted final height that includes other ethnic groups. The adjusted mean final height would be $183.8-0.4=183.4 \mathrm{~cm}$ in boys and 170.7 $-0.3=170.4 \mathrm{~cm}$ in girls. These numbers are an estimate of final height for all children living in The Netherlands, irrespective of ethnicity. As the differences between the Dutch and the nonDutch groups are substantial, separate growth references were constructed for children of Moroccan and Turkish decent, the two largest minorities in The Netherlands. These will be presented elsewhere.

We found that the height difference between the north and the south of The Netherlands has diminished since 1997. This was seen irrespective of child and parental educational levels. This change could be explained by factors such as fewer health inequalities or changes in national motility, in other words more migration between geographical regions. However, we found no evidence indicating a reduction of health inequalities between these regions, and there have been no major shifts in motility in The Netherlands since 1997 that could explain the phenomenon (17). Random sampling variation between the 1997 and 2009 study may have contributed to the smaller north-south difference. However, both studies were nationally representative. The study population of the Fifth Dutch Growth Study was large and randomly selected, and advanced imputation techniques were carried out for underrepresented groups to obtain a representative sample. Although we do not have a firm explanation for the reduction in height inequality between the north and the south of The Netherlands, the $1.6 \mathrm{~cm}$ (boys) and $1.4 \mathrm{~cm}$ (girls) difference in 21 year olds seem very plausible because they are similar to the $2 \mathrm{~cm}$ north-south difference found in a large Dutch study based on self-reported growth data (18).

It is remarkable that the difference in mean height SDS for children with lower and higher education levels has increased since 1997. This suggests that the inequality associated with education has increased. We found no explanation for this in the literature of national registries. It should be noted that there have been no significant changes in the mean height SDS in any of the categories since 1997. Monitoring this trend is important because larger height differences can be a sign of increasing health inequalities.

The upward secular height trend has slowed in most Northern European countries $(2,6)$. Conscript data show that height in Danish and Norwegian men remained stable between 2000 and 2009, and an earlier study based on self-reported data from Dutch adults also indicated that the secular increase in height had come to a halt (18-20). Despite the stagnating secular trend, the Dutch are still the tallest people in the world, followed 
directly by the Danish, who are reported to have a mean height of $183.7 \mathrm{~cm}$ (men) and $168.6 \mathrm{~cm}$ (women), and the Norwegians, with averages of $182 \mathrm{~cm}$ (men) and $169 \mathrm{~cm}$ (women) $(21,22)$. Pineau et al. (23) found boys in the Dinaric Alps to be $1.5 \mathrm{~cm}$ taller than their Dutch counterparts, whereas girls reach heights similar to their Dutch counterparts. Although this study looks at a region rather than a country, and corrects boys' height for growth after the age of $17 \mathrm{y}$, it indicates that young adults from this region in Eastern Europe are also tall. In fact, men in the Balkans were already among the tallest in Europe in the 19th century (11). Future studies of population height are expected to reveal whether the maximum mean population height is indeed $184 \mathrm{~cm}$ for boys and 171 for girls. The new Dutch reference charts are available at http://www.tno.nl/growth.

\section{METHODS}

\section{Data Sources}

Data for the earlier Dutch growth studies were collected in 1955, 1965,1980 , and 1997 and published elsewhere (2,24-26). The Fifth Dutch Growth Study was a cross-sectional study that collected data for a representative sample of children aged 0-21 y in The Netherlands between May 2008 and October 2009. The sample was stratified by region (regions of Municipal Health Services), sex, and age in line with national distributions (27). Until the age of $4 \mathrm{y}$, measurements were performed during regular periodical health examinations in 28 Well Baby Clinics at the ages of $1,2,3,6,9,12,15,18,21,24,30,36$, and 45 mo. Between the ages of 4 and $8 \mathrm{y}$, children were measured at 23 Municipal Health Service offices during two regular preventive health assessments performed at the ages of $\sim 5.5$ and $7.5 \mathrm{y}$. From the age of $9 \mathrm{y}$ onward, children were invited personally by the Municipal Health Services after being selected in an age- and sex-stratified random sampling procedure from the registers of the Municipal Register Office. Furthermore, we conducted measurements at randomly selected primary and secondary schools, at two colleges and two universities across the country, and at a national youth festival. The collection was supplemented by data from two recent large, high-quality studies performed by trained staff at primary schools in Amsterdam (Municipal Health Services in Amsterdam) and at a vocational education institution in the east of The Netherlands (Deltion College Zwolle/OPOZ VU-Windesheim). Random samples from these data ( $n=270$ and $n=342$, respectively) were added to the data for this study.

\section{Ethics Statement}

Data collection for growth studies is a part of routine youth health care in The Netherlands and is not regarded as medical research. Before the measurement, oral consent was obtained from each child (and from the parent when children were younger than 16 y). Cooperation, or lack thereof, was recorded on the questionnaire. Data were analyzed anonymously. The Medical Ethics Review Board of Leiden University Medical Center approved the study and the manner in which consent was obtained.

\section{Exclusion Criteria}

Exclusion criteria for the Fifth Dutch Growth Study were similar to those for the previous Dutch growth studies: children with diagnosed growth disorders and those on growth-interfering medication were excluded (2.4\% of the total population). Children with one or two parents born outside The Netherlands (28) were excluded from the analyses presented in this article. Results with respect to children of Turkish and Moroccan origin will be described elsewhere.

\section{Measurements}

Trained health-care professionals carried out the standardized measurements. Infant length was measured to the nearest $0.1 \mathrm{~cm}$ in the supine position until 2 y of age. From 2 y of age onward, standing height was measured to the nearest $0.1 \mathrm{~cm}$. The children's demographic characteristics were obtained from the parents or from adolescents themselves by health-care professionals using a questionnaire.

\section{Variable Definitions}

The sample was divided into five geographical regions: North (Friesland, Groningen, Drenthe), East (Overijssel, Gelderland, Flevoland), West (Noord-Holland, Zuid-Holland, Utrecht - not including the four major cities), South (Zeeland, Noord-Brabant, Limburg), and the four major Dutch cities (Amsterdam, Rotterdam, Utrecht, and The Hague). The educational level of the child was determined at the time of measurement. If an adolescent older than $15 \mathrm{y}$ had left the educational system, the highest completed education was recorded. The educational level of the parents was defined as the educational level of the highest educated parent and broken down into low, middle, high, and unknown (29). For the purposes of data cleaning and the comparison of height changes between 1997 and 2009, SDS were calculated for each age using the 1997 height references $(2,30)$.

\section{Statistical Analyses}

Data were cleaned using descriptive statistics that included frequency tables, contingency tables, and scatter plots. Outliers, defined as values more than +5 SDS or less than -5 SDS, were checked for data entry errors and corrected wherever possible. If no correction was possible, these measurements were considered erroneous and defined as missing. The distributions for child and parental educational levels and for geographical regions were compared with the national distributions (31) to check for representativeness. We used the multivariate imputation by chained equation method $(32,33)$ to correct for educational levels or geographical regions that were underrepresented. The imputation model was based on age, sex, height SDS, weight SDS, waist SDS, hip SDS, parental height, birth weight, ethnicity, socioeconomic status score (34), educational levels of the children and parents, and geographical region. Passive imputation was performed on the interactions between age and region, age and all SDS, age squared, and age squared and all SDS. There was no adjustment for the transition from length to height measurements, given that the age of the transition from length to height measurement differs from child to child in daily practice. Length and height were smoothly joined.

SDS reference values for height by age in 2009 were calculated using the LMS method (35). For these calculations, the data of 146 children aged 22-25 y were added to the dataset to obtain stable-fit results at the age of $21 \mathrm{y}$. These subjects were excluded from further analysis. The LMS method calculates three smooth curves representing skewness (L curve), the median (M curve), and coefficient of variation (S curve) to establish SDS lines. L values of 1 indicate normality, and smaller values represent progressively greater skewness. The $M$ curve is the 0 SDS line or 50th centile curve. The $S$ curve defines the coefficient of variation, and when multiplied by 100 , it can be interpreted as a percentage. The smoothing parameters (effective degrees of freedom) for the L, $\mathrm{M}$, and S curves were chosen by creating worm plots: local detrended quantile-quantile plots of the SDS of the reference samples across 16 age groups (36). A log transformation was applied to the age axis. The curves were fitted as cubic splines. Finally, estimates were made of the age-related SDS reference values for height in 2009.

Differences in mean heights between the samples of 2009, 1997, 1980, 1965, and 1955 were computed for each age group. "Mean height" in this article refers to the 50th percentile of the reference charts, unless otherwise indicated. Children from the 2009 study with a birth weight of $<2,500 \mathrm{~g}$ were not excluded from the comparisons because their inclusion has only a slight effect on mean height by age and because, as in 1997, they were included in the calculation of the height references.

Multivariate analysis (ANOVA) was conducted to assess the associations and trends for the demographic variables (geographical region, child educational level, and parental educational level) with height SDS in 2009 and differences between 1997 and 2009. Consequently, the values were corrected for the effects of the other two factors.

$\mathrm{R}$ version 2.9.0 ( $\mathrm{R}$ development core team, Vienna, Austria) with the GAMLSS package (37) was used for imputation and for estimating 
the height SDS reference values. All other statistical analyses were performed in SPSS version 17.0 for Windows (SPSS, Chicago, IL).

\section{ACKNOWLEDGMENTS}

We thank all the children, their parents, and the community health care workers who participated in this study. We thank ActiZ and GGD-Nederland for their cooperation in the study. We thank Deltion College/OPOZ VU-Windesheim and GGD Amsterdam for kindly providing their data sets.

\section{STATEMENT OF FINANCIAL SUPPORT}

This study was funded by the Dutch Ministry of Welfare and Sport (grants 310434, 312617, and 315319). The researchers were independent of the funder.

\section{REFERENCES}

1. Hauspie RC, Vercauteren M, Susanne C. Secular changes in growth. Horm Res 1996;45:Suppl 2:8-17.

2. Fredriks AM, van Buuren S, Burgmeijer RJ, et al. Continuing positive secular growth change in The Netherlands 1955-1997. Pediatr Res 2000;47:316-23.

3. Batty GD, Shipley MJ, Gunnell D, et al. Height, wealth, and health: an overview with new data from three longitudinal studies. Econ Hum Biol 2009;7:137-52.

4 Wieringen van JC. Secular growth changes. In: Falkner F, Tanner JM, eds. Human Growth. New York: Plenum Press, 1988:307-31.

5. Drukker J, Tassenaar PG. Paradoxes of modernization and material wellbeing in The Netherlands during the 19th century. In: Steckel RH, Floud $\mathrm{R}$, eds. Health and Welfare During Industrialization. Chicago: Chicago University Press, 1997:331-79.

6. Gohlke B, Woelfle J. Growth and puberty in German children: is there still a positive secular trend? Dtsch Arztebl Int 2009;106:377-82.

7. Komlos J. The recent decline in the height of African-American women. Econ Hum Biol 2010;8:58-66.

8. Centraal Bureau voor de Statistiek, (Statistics Netherlands). [Dutch Gross DomesticProduct2000-2009]. (http://statline.cbs.nl/StatWeb/publication/? $\mathrm{VW}=\mathrm{T} \& \mathrm{DM}=\mathrm{SLNL} \& \mathrm{PA}=71015 \mathrm{NED} \& \mathrm{D} 1=0 \& \mathrm{D} 2=0 \& \mathrm{D} 3=\mathrm{a} \& \mathrm{HD}=-$ 120503-1943\&HDR=T\&STB=G1,G2). Accessed 3 May 2012.

9. Boelhouwer J. [Life situation, happiness and quality of life]. In: Bijl R, Boelhouwer J, Cloin M, Pommer E, eds. [The Social State of The Netherlands 2011]. Den Haag: Sociaal Cultureel Planbureau, 2011:307.

10. Boelhouwer J. [Life situation]. In: Roes T, ed. [Social State of The Netherlands 2001]. Den Haag: Sociaal Cultureel Planbureau, 2001:241.

11. Komlos J. Anthropometric evidence on economic growth, biological wellbeing and regional convergence in the Habsburg Monarchy, c. 1850-1910. Cliometrica 2007;1:211-37.

12. Berkey CS, Colditz GA, Rockett HR, Frazier AL, Willett WC. Dairy consumption and female height growth: prospective cohort study. Cancer Epidemiol Biomarkers Prev 2009;18:1881-7.

13. Productschap Zuivel (Dutch Dairy Board). EU and other countries - consumption. In: Productschap Zuivel (Dutch Dairy Board), ed. [Statistical Yearbook 2010]. Zoetermeer, The Netherlands: Productschap Zuivel (Dutch Dairy Board), 2011:83-107.

14. Schönbeck Y, Talma H, van Dommelen P, et al. Increase in prevalence of overweight in Dutch children and adolescents: a comparison of nationwide growth studies in 1980, 1997 and 2009. PLoS ONE 2011;6(11):e27608.

15. Freedman DS, Khan LK, Serdula MK, Dietz WH, Srinivasan SR, Berenson GS. Relation of age at menarche to race, time period, and anthropometric dimensions: the Bogalusa Heart Study. Pediatrics 2002;110:e43.
16. Freedman DS, Khan LK, Serdula MK, Dietz WH, Srinivasan SR, Berenson GS. The relation of menarcheal age to obesity in childhood and adulthood: the Bogalusa heart study. BMC Pediatr 2003;3:3.

17. Centraal Bureau voor de Statistiek, (Statistics Netherlands). [Population Development CBS]. (http://statline.cbs.nl/StatWeb/selection/?DM=SLNL $\& P A=37259 N E D \& V W=T)$. Accessed 7 July 2011.

18. Frenken F. [Deceleration of Height and Weight Increase]. Voorburg/Heerlen, The Netherlands: Centraal Bureau voor de Statistiek (Statistics Netherlands), Demographic Statistics, 4th quarter 2007, 2007.

19. Denmark Statistics. Population and elections. In: Agerskov U, Bisgaard MP, eds. Statistical Yearbook 2011. Copenhagen, Denmark: Statistics Denmark, 2011:53.

20. Norway Statistics. Statistical Yearbook of Norway 2010 - Health and Social Conditions. (http://www.ssb.no/english/yearbook/2010/tab/tab-108.html). Accessed 3 May 2012.

21. Garcia J, Quintana-Domeque C. The evolution of adult height in Europe: a brief note. Econ Hum Biol 2007;5:340-9.

22. Norway Helsedirektoratet. [Physical Fitness Among Adults and the Elderly in Norway - Results From a Survey in 2009-2010]. Oslo, Norway: Helsedirektoratet Norway, 2010.

23. Pineau JC, Delamarche P, Bozinovic S. [Average height of adolescents in the Dinaric Alps]. C R Biol 2005;328:841-6.

24. Wijn de JF, Haas de JH. [Growth Diagrams for Ages 1-25 Years in The Netherlands]. Leiden, The Netherlands: Nederlands Instituut voor Praeventieve Geneeskunde, 1960.

25. Wieringen van JC, Wafelbakker F, Verbrugge HP, Haas de JH. [Growth Diagrams 1965 The Netherlands]. Leiden/Groningen, The Netherlands: Nederlands Instituut voor Praeventieve Geneeskunde/Wolters Noordhoff, 1965.

26. Roede MJ, Wieringen van JC. [Growth diagrams 1980: Netherlands third nationwide survey]. Tijdschr Soc Gezondheidsz 1985;63:1-34.

27. Centraal Bureau voor de Statistiek, (Statistics Netherlands). [Demographic statistics 2006]. (http://statline.cbs.nl/StatWeb/selection/?DM=SLNL\&PA $=37713 \& V W=T)$. Accessed 12 November 2007.

28. Keij I. [Standard definition immigrants]. Index 2000;10:24-5.

29. Verweij A. [Categorising educational level]. In: Volksgezondheid Toekomst Verkenning, ed. [The Dutch 2008 Public Health Status and Forecast Report]. Bilthoven, The Netherlands: RIVM, 2008.

30. Cole TJ. The LMS method for constructing normalized growth standards. Eur J Clin Nutr 1990;44:45-60.

31. Centraal Bureau voor de Statistiek, (Statistics Netherlands). [Demographic statistics 2008]. (http://statline.cbs.nl/StatWeb/selection/?DM=SLNL\&PA= 37713\&VW). Accessed 24 July 2009.

32. Buuren van S, Groothuis-Oudshoorn K. MICE: multivariate imputation by chained equations in R. J Stat Softw 2011;45:1-67.

33. Buuren van S. Selection issues. In: Buuren van S, ed. Flexible Imputation of Missing Data. Boca Raton, FL: Chapman \& Hall/CRC Press, 2012:212-8.

34. Sociaal en Cultureel Planbureau (Netherlands Institute for Social Reseach). [Status scores 2006]. (http://www.scp.nl/Organisatie/Onderzoeksgroepen/ Wonen_Leefbaarheid_Veiligheid/Lopend_onderzoek_van_WLV/Statusscores). Accessed 11 January 2010.

35. Cole TJ, Green PJ. Smoothing reference centile curves: the LMS method and penalized likelihood. Stat Med 1992;11:1305-19.

36. Buuren van S, Fredriks M. Worm plot: a simple diagnostic device for modelling growth reference curves. Stat Med 2001;20:1259-77.

37. Stasinopoulos DM, Rigby RA. Generalized additive models for location scale and shape (GAMLSS) in R. J Stat Softw 2007;23:1-46. 